\title{
INTRATHECAL MORPHINE PLUS GENERAL ANESTHESIA IN CARDIAC SURGERY: EFFECTS ON PULMONARY FUNCTION, POSTOPERATIVE ANALGESIA, AND PLASMA MORPHINE CONCENTRATION
}

\author{
Luciana Moraes dos Santos, 'Verônica Cavani Jorge Santos, ${ }^{\text {II }}$ Silvia Regina Cavani

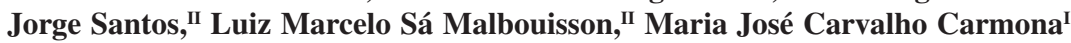

doi: $10.1590 / \mathrm{S1807-59322009000400003}$

dos Santos LM, Santos VCJ, Santos SRCJ, Malbouisson LMS, Carmona MJC. Intrathecal morphine plus general anesthesia in cardiac surgery: effects on pulmonary function, postoperative analgesia, and plasma morphine concentration. Clinics. 2009;64(4):279-85.

OBJECTIVES: To evaluate the effects of intrathecal morphine on pulmonary function, analgesia, and morphine plasma concentrations after cardiac surgery.

INTRODUCTION: Lung dysfunction increases morbidity and mortality after cardiac surgery. Regional analgesia may improve pulmonary outcomes by reducing pain, but the occurrence of this benefit remains controversial.

METHODS: Forty-two patients were randomized for general anesthesia (control group $n=22$ ) or $400 \mu \mathrm{g}$ of intrathecal morphine followed by general anesthesia (morphine group $n=20$ ). Postoperative analgesia was accomplished with an intravenous, patientcontrolled morphine pump. Blood gas measurements, forced vital capacity (FVC), forced expiratory volume (FEV), and FVC/FEV ratio were obtained preoperatively, as well as on the first and second postoperative days. Pain at rest, profound inspiration, amount of coughing, morphine solicitation, consumption, and plasma morphine concentration were evaluated for 36 hours postoperatively. Statistical analyses were performed using the repeated measures ANOVA or Mann-Whiney tests $(* \mathrm{p}<0.05)$.

RESULTS: Both groups experienced reduced FVC postoperatively $(3.24 \mathrm{~L}$ to $1.38 \mathrm{~L}$ in control group; $2.72 \mathrm{~L}$ to $1.18 \mathrm{~L}$ in morphine group), with no significant decreases observed between groups. The two groups also exhibited similar results for $\mathrm{FEV}_{1}(\mathrm{p}=0.085)$, $\mathrm{FEV} / \mathrm{FVC}(\mathrm{p}=0.68)$ and $\mathrm{PaO}_{2} / \mathrm{FiO}_{2}$ ratio $(\mathrm{p}=0.08)$. The morphine group reported less pain intensity (evaluated using a visual numeric scale), especially when coughing (18 hours postoperatively: control group $=4.73$ and morphine group $=1.80, \mathrm{p}=0.001)$. Cumulative morphine consumption was reduced after 18 hours in the morphine group (control group $=20.14$ and morphine group $=14.20$ $\mathrm{mg}, \mathrm{p}=0.037$ ). The plasma morphine concentration was also reduced in the morphine group 24 hours after surgery (control group= $15.87 \mathrm{ng} . \mathrm{mL}^{-1}$ and morphine group $=4.08 \mathrm{ng} \cdot \mathrm{mL}^{-1}, \mathrm{p}=0.029$ ).

CONCLUSIONS: Intrathecal morphine administration did not significantly alter pulmonary function; however, it improved patient analgesia and reduced morphine consumption and morphine plasma concentration.

KEYWORDS: Respiratory mechanics; Gas exchange; Cardiac surgery; Pain scores.

\section{INTRODUCTION}

Lung dysfunction after cardiac surgery is the most frequently reported cause of postoperative morbidity. ${ }^{1,2} \mathrm{In}$

\footnotetext{
${ }^{\text {I }}$ Department of Anesthesia, Heart Institute, Faculdade de Medicina da Universidade de São Paulo - São Paulo/SP, Brazil.

II Department of Clinical Pharmacology, Pharmaceutical Sciences School, Universidade de Sao Paulo - São Paulo/SP, Brazil.

Email: lumoraesrj@yahoo.com.br

Phone: 55163602.2211

Received for publication on October 28, 2008

Accepted for publication on December 09, 2008
}

fact, postoperative atelectasis occurs more frequently in patients undergoing cardiac surgery with cardiopulmonary bypass $(\mathrm{CPB})$ than in any other type of surgery ${ }^{3}$ In patients undergoing cardiac surgery, death caused by respiratory complications has been reported as being more frequent than that due to cardiac causes. ${ }^{4}$ Adequate perioperative analgesia enables full expansion of the chest, thereby contributing to reduce lung collapse in spontaneously breathing patients. This therapeutic intervention may reduce morbidity, hospital costs, and length of stay, thus improving patient quality of life and reducing the incidence of chronic pain. ${ }^{5}$ 
The impact of postoperative regional analgesia on major outcomes in non-cardiac surgery has been studied..$^{6-8}$ Small doses of opioids administered to the central nervous system provide adequate analgesia, reducing the risks of intravenous analgesic administration, such as respiratory depression, pruritus, nausea, and vomiting. However, in the cardiac surgical population, regional anesthesia techniques are not routinely applied due to the scarcity of supporting studies and administration risks associated with preoperative systemic anticoagulation ${ }^{9}$ Low doses of intrathecal morphine used to control postoperative pain has been shown to promote prolonged analgesia, ${ }^{5}$ and has been associated with a lower risk of hematoma formation compared to the epidural technique. ${ }^{10}$ Intrathecal morphine has been studied for several years in patients undergoing cardiac surgery, but these studies were primarily directed towards evaluation of pain control and hemodynamic stability, and did not consider its possible impact of intrathecal morphine on respiratory function recovery. ${ }^{11}$

The objective of this study was to evaluate the effects of intrathecal morphine on pulmonary function, postoperative analgesia, and morphine plasma concentrations in patients undergoing coronary artery bypass surgery $(\mathrm{CABG})$ with cardiopulmonary bypass (CPB) in comparison to standard intravenous analgesia.

\section{MATERIALS AND METHODS}

After approval of the hospital ethics committee and collection of free informed consent, forty-two patients undergoing $\mathrm{CABG}$ with $\mathrm{CPB}$ and ranging in age from 18 to 80 years were included. Exclusion criteria were an ejection fraction below $40 \%$, contraindications to neuraxial blockage, coagulopathy, use of low-weight heparin, warfarin, intrathecal morphine, or a platelet aggregation inhibitor other than aspirin, systemic or local infection, combined procedures, and patients with a specific contraindication to the medication employed in this study. Preoperative aspirin use was not an exclusion criterion. Preoperative surgical risk was evaluated using Higgins Surgical Risk Scale for cardiac surgery, and patients were considered: (1) minimum risk, (2) low risk, (3) moderate, (4) high, (5) extreme risk ${ }^{12}$. The patients were randomly assigned to receive general anesthesia with prior administration of intrathecal morphine at a dosage of $400 \mu \mathrm{g}$ (morphine group $\mathrm{n}=20$ ) or general anesthesia alone (control group $n=22$ ) according to a simple computer-generated list.

\section{Anesthesia and surgical procedures}

On the day of the operation, the patients received 1 to
$2 \mathrm{mg} \mathrm{kg}^{-1}$ of midazolam orally 30 minutes before surgery, up to a maximal dose of $15 \mathrm{mg}$. Patients were monitored by continuous ECG and ST-analysis, pulse oximetry, and an invasive arterial line inserted in the right radial artery. In the morphine group, a 400- $\mu$ g intrathecal injection of morphine was administered using a 27-gauge spinal needle in the L3-L4 space prior to induction of general anesthesia. If intrathecal puncture was not successful after two attempts, the patient was excluded from the study.

After pre-oxygenation, general anesthesia was induced using $0.3 \mathrm{mg} / \mathrm{kg}$ of hypnomidate, $0.1 \mathrm{mg} \mathrm{kg}^{-1}$ of pancuroniun bromide, and $0.5 \mu \mathrm{g} \mathrm{kg}^{-1}$ of sufentanil first as a bolus, followed by a continuous infusion at $0.5 \mu \mathrm{g} \mathrm{kg} \mathrm{k}^{-1} \mathrm{~h}^{-1}$. Mechanical ventilation was initiated using a Cícero ventilator (Dräger ${ }^{\circledR}$, Germany) with a tidal volume of 8 $\mathrm{ml} \mathrm{kg}{ }^{-1}$, respiratory frequency of $12 \mathrm{ipm}$, oxygen inspired fraction of $0.6 \%$, and $5 \mathrm{~cm}$ of $\mathrm{H}_{2} \mathrm{O}$ PEEP. A nasoesophageal thermometer, bladder catheter, and central venous catheter were inserted after anesthesia induction. When judged necessary by the attending anesthesiologist, a pulmonary artery catheter was placed in the right internal jugular vein. Immediately after intubation and after CPB weaning, a lung expansion maneuver using an airway pressure of $30 \mathrm{cmH}_{2} \mathrm{O}$ for 20 seconds was performed to revert any intraoperative lung collapse. During CPB, hypnosis was maintained with a propofol infusion aimed at maintaining a calculated plasma propofol concentration of $2.5 \mathrm{ug} \mathrm{ml}^{-1}$ according to the Marsh model $^{13}$. All patients received $1 \mathrm{~g}$ of methylprednisolone intravenously before initiation of CPB according to the institutional protocol. Sufentanil infusion was terminated at the moment of skin suture.

After arrival in the intensive care unit (ICU), a patientcontrolled analgesia pump (PCA) programmed for a $1 \mathrm{mg}$ bolus of morphine with an administration interval locked at 5 minutes and free demand was installed. Dipyrone (30 mg $\mathrm{kg}^{-1}$ ) was administered if patients presented persistent pain despite the use of PCA. Tracheal extubation was performed when patients were fully awake and responsive to verbal commands, as well as when the peripheral oximetry was greater than $94 \%$, spontaneous respiratory frequency was greater than 10 , temperature was greater than $36^{\circ} \mathrm{C}$, and the patient was hemodynamically stable such that they were bleeding less than $100 \mathrm{ml} / \mathrm{h}$.

\section{Ventilatory and pain score evaluation}

Spirometry using an Easy One ${ }^{\circledR}$ portable spirometer (Niche Medical, West Leederville, Australia) was also performed preoperatively in the first and second postoperative days (POD) to measure forced vital capacity (FVC), forced expiratory volume in the first second (FEV1), 
and thus the FEV1/FVC ratio. Arterial blood samples were collected during the preoperative period, immediately before surgery, after anesthesia induction, at the end of surgery, and in the first and second postoperative days to evaluate the $\mathrm{PaO}_{2} / \mathrm{FiO}_{2}$ ratio. Pain was evaluated using a visual numeric scale from zero to ten at rest, at the time of profound inspiration, and after cough at 3, 6, 12, 18, 24, and 36 hours postoperatively. Morphine cumulative consumption and solicitation was also evaluated at the same times listed above. All postoperative pain, respiratory function, and morphine utilization measurements were obtained by individuals who were not involved in patient randomization and anesthesia administration.

Blood samples assessed for plasma morphine concentrations were collected intraoperatively, immediately after stopping sufentanil infusion, after 5, 15, 30, and 60 minutes, and after $3,6,12,18,24$, and 36 hours in the ICU. The blood samples were centrifuged at $10.000 \mathrm{rpm}$ for 10 minutes, and the supernatant was frozen at $-70{ }^{\circ} \mathrm{C}$ for later analysis. Plasma morphine concentrations were measured using a mass spectrophotometer.

\section{Sample size and statistical analysis}

A sample size of at least 36 patients was deemed necessary to detect a statistically significant decrease ( $\mathrm{p}<$ 0.05 ) in cumulative morphine consumption of $20 \%$ between the morphine and control group, assuming a standard deviation of $10 \mathrm{mg}$ in a single-tail paired Student's t-test using G Power 3 software (Heinrich-Heine-Universität Düsseldorf, Düsseldorf, Germany).

Statistical analyses were performed using SPSS 16.0 software (SPSS Inc., Chicago, Ilinois). The normal distribution of the collected data was confirmed by means of the Kolmogorov-Smirnov test. Demographic and surgical data were compared between groups using the unpaired Student's t-test. Spirometric variables were compared over time between the groups using repeated measures analysis of variance, followed by the Student-Neumann-Keuls post hoc test when necessary. Pain scores and cumulative morphine consumption were analyzed by means of the Friedman test, followed by the Mann-Whitney test when necessary. All data are presented as mean values \pm standard deviation, error means, or as otherwise described. The significance level was fixed at $5 \%$.

\section{RESULTS}

Patient characteristics and general variables are presented in Table 1. There were no differences between groups with regard to the variables represented in Table 1. Mean surgery duration and CPB length were similar in both groups (392 \pm 70 vs. $379 \pm 91$ minutes $)$ and ( $98 \pm 26$ vs. $95 \pm 38$ minutes $)$ ( $\mathrm{p}=0.606$ and $\mathrm{p}=0.780$, respectively). Minimal temperature values were $31.3 \pm 2.7^{\circ} \mathrm{C}$ in the control group and $30.7 \pm$ $2.7^{\circ} \mathrm{C}$ in the morphine group $(\mathrm{p}=0.456)$. All patients achieved hemodynamic stability in the immediate postoperative period, permitting weaning off of the vasoactive drugs within the first 24 hours. The total dose of sufentanil employed was $257.77 \mu \mathrm{g} \pm 81.41$ in the control group and $200.87 \mu \mathrm{g}$ \pm 55.11 in the morphine group ( $\mathrm{p}=0.012)$, and was related to the duration of surgery. Intrathecal morphine did not shorten the postoperative time to extubation between groups $(396 \pm 234 \mathrm{~min}$ in the control group and $349 \mathrm{~min} \pm 175$ in the morphine group, $\mathrm{p}=0.466$ ). None of the patients in our cohort developed respiratory failure after extubation or needed postoperative non-invasive ventilation. All intrathecal punctures were successful at the first or second attempt.

Table 1 - Sex, Age, IMC, Higgins Surgical Risk Scale, Extubation time, Surgical time, Extracorporeal duration, Minimal temperature at Extracorporeal Circulation between groups. Total dose of sufentanil. Values represent means \pm SD. $*$ Chisquare Test **Independent T-student Test, $\mathrm{p}<0.05$

\begin{tabular}{lccc}
\hline & Control & Morphine & p-value \\
\hline Sex $(\mathrm{M}: \mathrm{F})$ & $20: 02$ & $16: 04$ & $0.313^{*}$ \\
Age $($ years $)$ & $63.8 \pm 11.3$ & $60.9 \pm 7.6$ & $0.361^{* *}$ \\
BMI $\left(\mathrm{Kg} / \mathrm{cm}^{2}\right)$ & $27.1 \pm 3.1$ & $24.4 \pm 3$ & $0.071^{* *}$ \\
Higgins Surgical Risk Scale $(0-5)$ & $1.727 \pm 1.08$ & $2 \pm 1.21$ & $0.546^{* *}$ \\
Surgery Duration (min) & $392.5 \pm 70.30$ & $379,5 \pm 91,00$ & $0.606^{* *}$ \\
Tracheal Extubation Time $(\min )$ & $396.5 \pm 234.20$ & $349.1 \pm 175.10$ & $0.466^{* *}$ \\
CPB Time (min) & $98.27 \pm 26.90$ & $95.55 \pm 38.26$ & $0.790^{* *}$ \\
Minimal Temperature at CPB $\left({ }^{\circ} \mathrm{C}\right)$ & $31.30 \pm 2.70$ & $30.68 \pm 2.66$ & $0.456^{* *}$ \\
Total Dose of Sufentanil $(\mu \mathrm{g})$ & $257.77 \pm 81.41$ & $200.87 \pm 55.11$ & $0.012^{* *}$ \\
\hline
\end{tabular}

* Chi-square Test, ** Independent T Samples Test 
Table 2 - Forced Vital Capacity (FVC), Forced Expiratory Volume in the First Second (FEV1), and FEV1/FVC ratio at preoperative, and first and second postoperative days (P.O.D.) *ANOVA, $\mathrm{p}<0.05$

\begin{tabular}{llcccc}
\hline & Groups & Pre-op & 1 st $^{\circ}$ POD & 2nd POD & P-value* \\
\hline FVC & Control Group & $3.24 \pm 0.85$ & $1.45 \pm 0.60$ & $1.38 \pm 0.53$ & 0.0679 \\
& Morphine Group & $2.72 \pm 0.68$ & $1.18 \pm 0,45$ & $1.26 \pm 0.42$ & 0.085 \\
FEV1 & Control Group & $2.41 \pm 0.73$ & $1.06 \pm 0.46$ & $1.02 \pm 0.54$ & $0.95 \pm 0.26$ \\
& Morphine Group & $1.96 \pm 0.64$ & $0.90 \pm 0.32$ & $0.79 \pm 0.35$ & 0.685 \\
FEV1/FVC & Control Group & $0.75 \pm 0.11$ & $0.77 \pm 0.19$ & $0.78 \pm 0.15$ & $0.77 \pm 0.14$ \\
& Morphine Group & $0.74 \pm 0.14$ & & \\
\hline
\end{tabular}

No cases of spinal hematoma or treatable pruritus were observed. All patients were discharged from the ICU without postoperative complications.

\section{Gas exchange and Spirometric Analysis}

Both group presented a significant decrease in FVC and $\mathrm{FEV}_{1}$ during the first and second postoperative days, with no significant difference between the groups $(\mathrm{p}=0.068$ and 0.085 , respectively). The FEV1/FVC ratio did not differ between groups $(\mathrm{p}=0.68)$, as presented in Table 2 . In addition, the $\mathrm{PaO}_{2} / \mathrm{FiO}_{2}$ ratio did not differ between groups at any time point $(\mathrm{p}>0.05)$, as presented in Figure 1 .

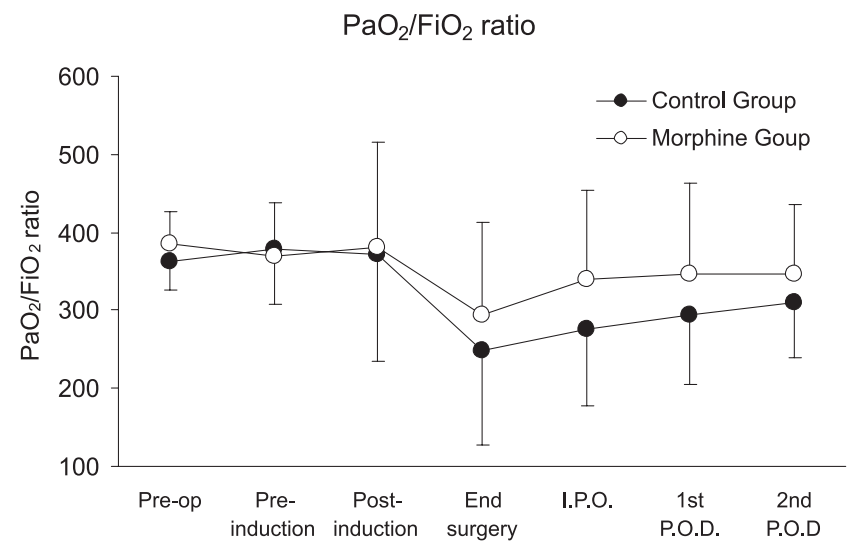

Figure $1-\mathrm{PO}_{2} / \mathrm{FIO}_{2}$ ratio between groups, $\mathrm{p}=0.078$ (means \pm DP). P.O.D $=$ postoperative day. ANOVA, ${ }^{*} \mathrm{p}<0.05$

\section{Pain scores, morphine consumption, and plasma con-} centrations

The intensity of pain at rest and with cough was significantly lower in the morphine group at $12,18,24$, and 36 hours postoperatively when compared to the control group ( $\mathrm{p}<0.05$ ), as shown in panels A and C of Figure 2. With profound inspiration, patients in the morphine group reported pain levels that were significantly less intense at 12,18 , and 24 hours after surgery (panel B of Figure 2). The venous morphine solicitation count was lower in the morphine group

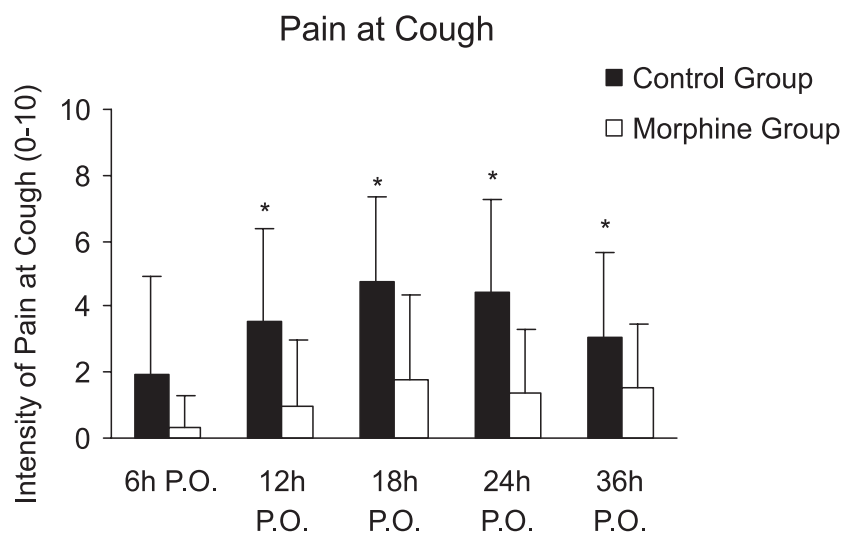

Figure 2 - Intensity of Pain between groups (means \pm SEM). A. Pain at rest (pvalue at $12,18,24$, and $36 \mathrm{~h}$ was $0.0095 ; 0.0013 ; 0.0089 ; 0.0446$, respectively). B. Pain upon profound inspiration (p-values were $0.0291 ; 0.0005 ; 0.0004$, respectively). C. Pain upon cough (p-values at $12,18,24$, and 36 hours were $0.0019 ; 0.0010 ; 0.0218 ; 0.0145$. - Mann-Whitney Test, $\mathrm{p}<0.05$ )

at 18 (control group $=108.3 \pm 213.8$ and morphine group $=$ $20.2 \pm 30.3$ ) and 24 hours (control group $=144.4 \pm 251.2$ and morphine group $=32.4 \pm 38.05)(\mathrm{p}<0.05)$. Cumulative morphine consumption was also reduced in the morphine group at 18 (control group $=20.14 \pm 17.73 \mathrm{mg}$ and morphine group $=14.10 \pm 26.15 \mathrm{mg}$ ), 24 (control group $=27.82 \pm 22.77$ $\mathrm{mg}$ and morphine group= $13.55 \pm 10.49 \mathrm{mg}$ ), and 36 hours (control group $=38.50 \pm 26.70$ and morphine group $=24.30 \pm$ 14.59) postoperatively (Figure 3), as well as upon extubation

\section{Cumulative Morphine Consumption}

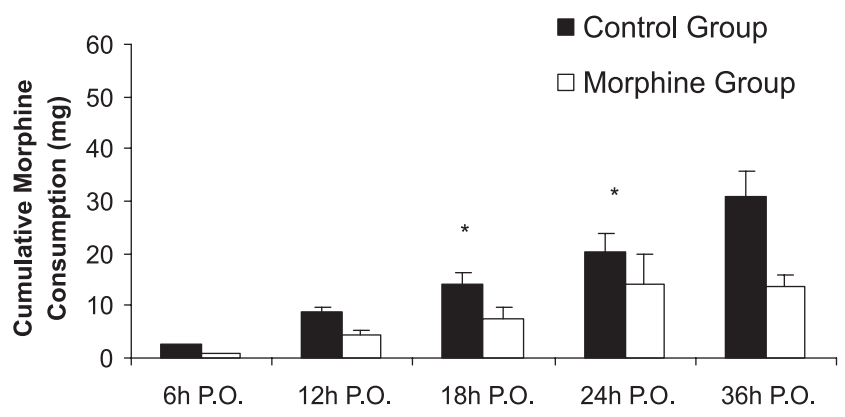

Figure 3 - Cumulative morphine consumption between groups (means \pm SEM). P-values at 18 and 24 hours were 0.0373 and 0.0283 , respectively. Mann-Whitney Test, *p<0.05 


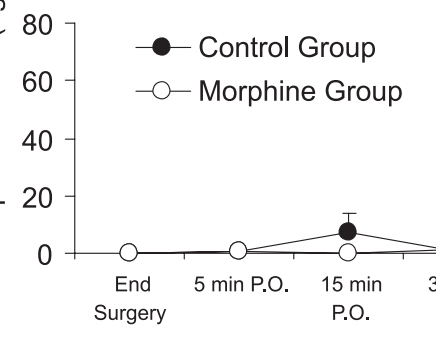

Figure 4 - Plasma Morphine Levels between groups, p-value $=0.029$ at 24 hours. Mann-Whitney, ${ }^{*} \mathrm{p}<0.05$

(control group $=3.32 \pm 8.17 \mathrm{mg}$ and morphine group $=0.15$ $\pm 0.49 \mathrm{mg})(\mathrm{p}<0.05)$. Plasma morphine levels were zero at the end of surgery in both groups. However, plasma levels were significantly reduced in the morphine group during the postoperative period 24 hours after the operation (control group $=15.87 \pm 18.05 \mathrm{ng} \mathrm{mL}^{-1}$ and morphine group $4.08 \pm$ $5.28 \mathrm{ng} \mathrm{mL}^{-1}, \mathrm{p}=0.029$ ), as presented in Figure 4. Nine patients in the control group and five patients in the morphine group requested rescue analgesia with dipyrone $(\mathrm{p}=0.460)$.

\section{DISCUSSION}

In the present study, intrathecal morphine administration in patients undergoing coronary artery bypass graft reduced pain scores, postoperative morphine solicitation, and morphine consumption and its plasma concentration. However, despite better analgesic control, no significant improvements in spirometry or gas exchange were observed.

Respiratory system dysfunction is the most prevalent organic complication after cardiac surgery, even in the absence of preoperative pulmonary disease ${ }^{1}$. Perioperative atelectasis leads to a pulmonary ventilation/perfusion mismatch that likely serves as a major cause of shunt and hypoxemia after cardiopulmonary bypass. ${ }^{14}$ The impact of postoperative analgesia techniques on pulmonary function outcome has been well studied in non-cardiac surgery, but few studies to date have examined this matter in cardiac surgery. ${ }^{8}$ A study that enrolled 113 patients submitted for different types of cardiac surgery observed that thoracic epidural analgesia (TEA) combined with general anesthesia followed by patient-controlled thoracic epidural analgesia offered no major advantages with respect to lung function, length of hospital stay, quality of recovery, or morbidity when compared to general anesthesia alone, with both groups followed by patient-controlled analgesia with intravenous morphine..$^{15}$ In contrast, a meta-analysis including 15 trials enrolling 1.178 patients suggested that TEA significantly reduced the risk of pulmonary complications (OR 0.41), time to tracheal extubation by 4.5 hours, and analog pain scores at rest and with activity. ${ }^{9}$

In the present study, intrathecal instead of epidural morphine was used because there is no evidence for analgesia superiority between them. However, the risk of spinal hematoma is lower with the intrathecal technique, ${ }^{16}$ especially with the required anticoagulation prior to cardiac surgery.

The last two meta-analyses used to evaluate the use of intrathecal morphine in cardiac surgery did not reveal a correlation between the efficacy of pain control and better respiratory outcome, ${ }^{3,11}$ likely because these studies did not employ lung function as an end-point ${ }^{11}$. Some of these studies described no improvement of pain control ${ }^{10}$ or modest reduction of pain scores,${ }^{11}$ with higher doses correlating with better postoperative analgesia ${ }^{17}$ as well as longer time to extubation. ${ }^{18}$ In line with the beginning of the fast-track era and its goal to decrease the intubation time after surgery, changes in anesthesia techniques and a reduction in the dose of intrathecal morphine were previously associated with a decreased time to extubation, ${ }^{20}$ with some cases of prolonged respiratory depression. ${ }^{21}$ A previous study compared intrathecal morphine doses of 250 and $500 \mu \mathrm{g}$ and placebo, and showed the superiority of intrathecal analgesia, without alterations in gas exchange ${ }^{19}$ or an increase in time to extubation. ${ }^{22}$ In the present study, the selected dose of 400 $\mu \mathrm{g}$ of morphine had no effect on time to tracheal extubation in the postoperative period. According to our results, use of low doses of intrathecal morphine can decrease the intensity of postoperative pain at different times, such as at rest, upon profound inspiration, and upon cough. This suggests that not only does intrathecal morphine provide better analgesia at rest, but also during activities that support walking, respiratory maneuvers, and the use of incentive spirometry. This is important to ensure the quality of patient recovery, since it has been demonstrated that respiratory physiotherapy may reduce rates of pulmonary complications. ${ }^{23-25}$ 
Improved analgesia may allow for a decrease in the solicitation and consumption of postoperative analgesics, resulting in lower plasma analgesic levels, as observed in this study. A previous cardiac surgery study that also used intrathecal morphine revealed a venous consumption of 13.5 $\mathrm{mg}$ at a dose of $250 \mu \mathrm{g}$, and a consumption of $11.7 \mathrm{mg}$ of morphine with an intrathecal dose of $500 \mu \mathrm{g}$ compared to $21.7 \mathrm{mg}$ in the placebo group 24 hours after the operation. ${ }^{22}$ In a meta-analysis, 668 patients undergoing cardiac surgery were reported to consume $11 \mathrm{mg}$ of intravenous morphine in intrathecal group . 9

The importance of studying the plasma concentration of morphine as a marker for progress in the of treatment of pain was considered by Bonica in 1985, but only a few studies have investigated this idea ${ }^{26}$ Only one study has been published regarding plasma morphine concentrations during patient control analgesia techniques ${ }^{27}$ and no studies reported intrathecal morphine use in the postoperative period or its correlation with pain scores. In patients undergoing hysterectomy with postoperative PCA, an increase in plasma morphine levels resulted in clinical effects 6 to 12 hours after surgery. This lag could be explained by the delay in morphine passing through the hematoencephalic barrier. After this period, a significant reduction in morphine consumption and pain scores was observed, and this can be explained by maintenance of a steady-state level of morphine sufficient to maintain an effective level of analgesia. ${ }^{27}$ Mutations in the opioid $\mu$ receptor were described to support the interindividual variability theory in the population and its possible influences on the use of morphine. ${ }^{28-30}$

Although the number of patients in our study was insufficient to fully evaluate the adverse effects of intrathecal morphine, no cases of spinal hematoma or treatable pruritus were observed in the present study. Previous studies utilizing doses between $5-24 \mu \mathrm{g} \mathrm{kg}^{-1}$ for cardiac surgery described a $30 \%$ incidence of pruritus ${ }^{21}$ which is the most common symptom observed after morphine treatment. Fortunately, this common side effect becomes severe in only $1 \%$ of cases. ${ }^{31}$ The absence of an intrathecal puncture in the control group may have limited our ability to observe adverse effects.

Despite the risk of spinal hematoma, the use of intrathecal analgesia in cardiac surgery ${ }^{32}$ has increased. This increase may be explained by the demand for better analgesia with chest tubes, sternotomy, deambulation, and physiotherapy maneuvers in the absence of a trained pain management team and patient-control pumps. Thus, our study has direct clinical applications. Future studies are being conducted to study the effects of pain control on quality of life, satisfaction, and postoperative recovery, since no additional benefits of intrathecal morphine beyond pain control have been shown until now. None of these quality of life or recovery variables have been correlated with better pain scores, but a modest reduction in satisfaction was shown in the presence of adverse effects. ${ }^{33}$ Considering the risks of nerve blockade and required anticoagulation in cardiac surgery, further efforts are required to identify better pain control to ensure better patient outcomes.

\section{REFERENCES}

1. Canver CC, Chanda J. Intraoperative and postoperative risk factors for respiratory failure after coronary bypass. The Annals of thoracic surgery. 2003;75:853-7.

2. Hein OV, Birnbaum J, Wernecke KD, Konertz W, Jain U, Spies C. Threeyear survival after four major post-cardiac operative complications. Critical care medicine. 2006;34:2729-37.

3. Weissman C. Pulmonary complications after cardiac surgery. Seminars in cardiothoracic and vascular anesthesia. 2004;8:185-211.

4. Welsby IJ, Bennett-Guerrero E, Atwell D, White WD, Newman MF, Smith PK, et al. The association of complication type with mortality and prolonged stay after cardiac surgery with cardiopulmonary bypass. Anesthesia and analgesia. 2002;94:1072-8,

5. Practice guidelines for acute pain management in the perioperative setting: an updated report by the American Society of Anesthesiologists Task Force on Acute Pain Management. Anesthesiology. 2004;100:157381.
6. Rodgers A, Walker N, Schug S, McKee A, Kehlet H, van Zundert A, et al. Reduction of postoperative mortality and morbidity with epidural or spinal anaesthesia: results from overview of randomised trials. BMJ (Clinical research ed. 2000;16;321:1493.

7. Beattie WS, Badner NH, Choi P. Epidural analgesia reduces postoperative myocardial infarction: a meta-analysis. Anesthesia and analgesia. 2001;93:853-8

8. Ballantyne JC, Carr DB, deFerranti S, Suarez T, Lau J, Chalmers TC, et al. The comparative effects of postoperative analgesic therapies on pulmonary outcome: cumulative meta-analyses of randomized, controlled trials. Anesthesia and analgesia. 1998;86:598-612.

9. Liu SS, Block BM, Wu CL. Effects of perioperative central neuraxial analgesia on outcome after coronary artery bypass surgery: a metaanalysis. Anesthesiology. $2004 ; 101: 153-61$.

10. Ho AM, Chung DC, Joynt GM. Neuraxial blockade and hematoma in cardiac surgery: estimating the risk of a rare adverse event that has not (yet) occurred. Chest. 2000;117:551-5. 
11. Mathews ET, Abrams LD. Intrathecal morphine in open heart surgery. Lancet. 1980; 6;2:543.

12. Higgins TL, Estafanous FG, Loop FD, Beck GJ, Blum JM, Paranandi L. Stratification of morbidity and mortality outcome by preoperative risk factors in coronary artery bypass patients. A clinical severity score. Jama. 1992;6;267:2344-8.

13. Marsh B, White M, Morton N, Kenny GN. Pharmacokinetic model driven infusion of propofol in children. British journal of anaesthesia. 1991;67:41-8.

14. Tenling A, Hachenberg T, Tyden H, Wegenius G, Hedenstierna G. Atelectasis and gas exchange after cardiac surgery. Anesthesiology. 1998;89:371-8

15. Hansdottir V, Philip J, Olsen MF, Eduard C, Houltz E, Ricksten SE. Thoracic epidural versus intravenous patient-controlled analgesia after cardiac surgery: a randomized controlled trial on length of hospital stay and patient-perceived quality of recovery. Anesthesiology. 2006; 104:142-51.

16. Vandermeulen EP, Van Aken H, Vermylen J. Anticoagulants and spinalepidural anesthesia. Anesthesia and analgesia. 1994;79:1165-77.

17. Chaney MA, Smith KR, Barclay JC, Slogoff S. Large-dose intrathecal morphine for coronary artery bypass grafting. Anesthesia and analgesia. 1996;83:215-22.

18. Chaney MA, Nikolov MP, Blakeman BP, Bakhos M. Intrathecal morphine for coronary artery bypass graft procedure and early extubation revisited. Journal of cardiothoracic and vascular anesthesia. 1999;13:574-8

19. Vanstrum GS, Bjornson KM, Ilko R. Postoperative effects of intrathecal morphine in coronary artery bypass surgery. Anesthesia and analgesia. 1988;67:261-7.

20. Chaney MA. Intrathecal and epidural anesthesia and analgesia for cardiac surgery. Anesthesia and analgesia. 1997;84:1211-21.

21. Metz S, Schwann N, Hassanein W, Yuskevich B, Nixon T. Intrathecal morphine for off-pump coronary artery bypass grafting. Journal of cardiothoracic and vascular anesthesia. 2004;18:451-3.

22. Alhashemi JA, Sharpe MD, Harris CL, Sherman V, Boyd D. Effect of subarachnoid morphine administration on extubation time after coronary artery bypass graft surgery. Journal of cardiothoracic and vascular anesthesia. 2000;14:639-44.
23. Lena $\mathrm{P}$, Balarac $\mathrm{N}$, Arnulf JJ, Teboul J, Bonnet F. Intrathecal morphine and clonidine for coronary artery bypass grafting. British journal of anaesthesia. 2003;90:300-3.

24. Westerdahl E, Lindmark B, Eriksson T, Friberg O, Hedenstierna G, Tenling A. Deep-breathing exercises reduce atelectasis and improve pulmonary function after coronary artery bypass surgery. Chest. 2005;128:3482-8.

25. Westerdahl E, Lindmark B, Eriksson T, Hedenstierna G, Tenling A The immediate effects of deep breathing exercises on atelectasis and oxygenation after cardiac surgery. Scand Cardiovasc J. 2003;37:3637.

26. Bonica JJ. Advances in pain research and therapy. In: H.L.Fields, ed. Treatment of cancer pain: current status and future needs. New York: Raven Press. 1985:589-616.

27. Beck D.H.; Schenk MD, U.; Kox, W. J. Relation of morphine consumption and morphine plasma concentration during patient-controlled analgesia. European Journal of Anesthesiology. 2000;1-41:17.

28. Yokokawa N, Hiraga K, Oguma T, Konishi M. Relationship between plasma concentration of morphine and analgesic effectiveness. Postgraduate medical journal. 1991;67 Suppl 2:S50-4.

29. Chou WY, Wang CH, Liu PH, Liu CC, Tseng CC, Jawan B. Human opioid receptor A118G polymorphism affects intravenous patientcontrolled analgesia morphine consumption after total abdominal hysterectomy. Anesthesiology. 2006;105:334-7.

30. Landau R. One size does not fit all: genetic variability of mu-opioid receptor and postoperative morphine consumption. Anesthesiology. 2006;105:235-7.

31. Chaney MA. Side effects of intrathecal and epidural opioids. Canadian journal of anaesthesia. Journal canadien d'anesthesie. 1995;42:891903.

32. Goldstein S, Dean D, Kim SJ, Cocozello K, Grofsik J, Silver P, et al. A survey of spinal and epidural techniques in adult cardiac surgery. Journal of cardiothoracic and vascular anesthesia. 2001;15:158-68.

33. Liu SS, Wu CL. The effect of analgesic technique on postoperative patient-reported outcomes including analgesia: a systematic review. Anesthesia and analgesia. $2007 ; 105: 789-808$. 
